\title{
Effects of Baking, Roasting and Frying on Total Polyphenols and Antioxidant Activity in Colored Chickpea Seeds
}

\author{
Aharon Segev ${ }^{1}$, Hana Badani ${ }^{1}$, Liel Galili ${ }^{1}$, Ran Hovav ${ }^{1}$, Yoram Kapulnik ${ }^{1}$, Ilan Shomer ${ }^{2}$, \\ Shmuel Galili ${ }^{*}$ \\ ${ }^{1}$ Department of Agronomy and Natural Resources, Agricultural Research Organization, The Volcani Center, Bet Dagan, Israel; \\ ${ }^{2}$ Food Science Department, Agricultural Research Organization, The Volcani Center, Bet Dagan, Israel. \\ Email: "galilis@agri.gov.il
}

Received November $8^{\text {th }}, 2011$; revised January $29^{\text {th }}, 2012$; accepted February $6^{\text {th }}, 2012$

\begin{abstract}
Chickpea lines with colored testa (seed coat) contain high levels of polyphenolic compounds that exhibit high levels of antioxidant activity. In a previous study, we showed that common processing procedures, such as soaking and cooking, decrease the levels of these bioactive compounds and subsequent overall antioxidant activity. The observed reduction in total phenolic content was due to the movement of polyphenols from the seed coat to the soaking or cooking water. Here, the effects of baking, roasting and frying processes were examined in relation to total phenolic content (TPC), total flavonoid content (TFC) and ferric-reducing ability of plasma antioxidant activity (FRAP AA) of colored chickpea seeds. Baked, fried and roasted colored chickpea seeds had significantly higher levels of TPC, TFC and FRAP AA than regular cream- and beige-colored seeds subjected to the same treatments. In contrast to our previous results with soaking and cooking, baking, frying and roasting retained most of the TPC, TFC and FRAP AA in the final products. Thus, colored chickpeas subjected to these three processing methods might be considered a functional food in addition to its traditional role of providing dietary proteins.
\end{abstract}

Keywords: Colored Chickpea Seed; FRAP; Processing; Total Phenolics; Total Flavonoids

\section{Introduction}

Chickpea (Cicer arietinum L.) is an annual grain legume (pulse crop) that is extensively cultivated for human consumption throughout the world, including the Mediterranean basin, the Near East, Central and South Asia, East Africa, South and North America, and Australia. It is the second-most important pulse crop in the world (after dry bean), covering $15 \%$ (10.2 million ha) of the area dedicated to pulse cultivation and accounting for $14 \%(7.9$ million tons) of pulse production worldwide (FAOSTAT, $\mathrm{http} / /$ faostat.fao.org/default.aspx). In Israel, chickpea is the main pulse crop, grown on about 6000 to 10,000 ha spread throughout the country. Chickpea seeds vary in size, shape and color [1]. Based on these variations, chickpea cultivars are classified into two categories: kabuli and desi [2]. The kabuli-type seeds have a thin seed coat ranging in color from white to cream and a 100 -seed weight of 28 to $70 \mathrm{~g}$. Desi-type chickpea seeds have a thicker, irregularly shaped seed coat, which ranges in color from light tan to black, and a 100-seed weight of not more than $28 \mathrm{~g}$.

\footnotetext{
"Corresponding author.
}

Dry legumes, including chickpea, are a good source of protein, dietary fibers, minerals and bioactive polyphenols $[3,4]$, and they also contribute to polyphenol intake from other foods [5]. The antioxidant capacity [6], and antimutagenic [7-10], apoptosis-related [11] and antiproliferative effects of legumes are associated with the presence of phenolic compounds in the seeds [11-13]. The abundance of phenolic compounds implies that legumes, such as the common bean (Phaseolus vulgaris) [9], faba (broad) bean (Vicia faba) [14,15], beach pea (Lathyrus maritimus) [16], mung bean (Vigna radiata) [17], lentil (Lens culinaris) [18], peanuts [19] and chickpea (Cicer arietinum) [20-22] may be significant food sources for active antioxidants.

Amounts of polyphenols and flavonoids and antioxidant activity vary greatly among chickpea lines [4]. For example, in a previous study with chickpea, we found that isolated hulls from colored chickpea lines contain higher amounts of polyphenols and flavonoid compounds than those of regular beige-colored seeds, and exhibit high levels of antioxidant activity [4]. This variation in both seed coat color and antioxidant activity makes colored 
chickpea a strong potential subject of study as a functional food.

Chickpea is usually consumed after cooking [23], frying [24], baking [25] or roasting [23,26]. These processing procedures improve the flavor and palatability of the food product and increase its nutritional bioavailability by inactivating antinutritional factors [27,28]. However, they may also affect its bioactive compounds and antioxidant activity [20,21]. The objective of this study was to determine the effects of baking, frying and roasting on levels of bioactive compounds (polyphenols and flavonoids) and antioxidant activity in vitro, in different food stuffs made from chickpea accessions with different-colored seed coats to determine their respective potentials for use as functional foods.

\section{Materials and Methods}

\subsection{Plant Materials}

Two chickpea lines were used in this study. Line 731, a desi type with black seed coat, originally derived from the National Germplasm Resources Laboratory of the USDAARS, Beltsville, MD, USA, and cv. Zehavit, a commercial Israeli kabuli cultivar with cream seed coat. Both lines were produced in our laboratory.

\subsection{Baking}

Baking was performed in a digital breadmaker (Morphy Richards 48290) utilizing the basic white bread setting for $3 \mathrm{~h}$ that included: kneading for $10 \mathrm{~min}$ at room temperature (RT), rising for $20 \mathrm{~min}$ at $\mathrm{RT}$, second kneading for $15 \mathrm{~min}$ at $30^{\circ} \mathrm{C}$, rising for $70 \mathrm{~min}$ at $32^{\circ} \mathrm{C}$ and baking for $65 \mathrm{~min}$ at $121^{\circ} \mathrm{C}$. Chickpea flour was made by grinding the seeds to a fine powder (60 mesh). Chickpea bread was made from dough containing $400 \mathrm{~g}$ chickpea flour and $225 \mathrm{ml}$ tap water. Samples were taken from the dough, and from the crust and inside parts of the baked bread. All samples were freeze-dried and kept at $4^{\circ} \mathrm{C}$ until use.

\subsection{Frying}

Frying was performed in a deep fryer (Graetz DF-730). Chickpea seeds $(70 \mathrm{~g})$ were soaked at RT in $500 \mathrm{ml}$ of tap water overnight. Soaked seeds were then removed from the soaking water and ground with a small amount of tap water (about $10 \mathrm{ml}$ ) in a blender. Small balls (falafel balls) of this dough were fried in canola oil preheated to $190^{\circ} \mathrm{C}$ for 5, 10 and $15 \mathrm{~min}$. Samples were taken from the soaked seeds, dough, and inside and crusted parts of the falafel ball. All samples were freeze-dried, defatted and kept at $4^{\circ} \mathrm{C}$ until use.

\subsection{Roasting}

Two types of roasting (wet and dry) were performed. For wet roasting, three samples of chickpea seeds, $20 \mathrm{~g}$ each, were separately soaked in $100 \mathrm{ml}$ tap water, overnight. For dry roasting, dry seeds were used directly without presoaking. All samples (wet or dry) were roasted at $125^{\circ} \mathrm{C}$, $150^{\circ} \mathrm{C}$ and $175^{\circ} \mathrm{C}$ for $30 \mathrm{~min}$ in a Philco kitchen oven. Roasted seeds were freeze-dried and kept at $4^{\circ} \mathrm{C}$ until use.

\subsection{Polyphenol Extraction}

Samples of each treatment were ground into a fine powder (60 mesh) in a Retsch MM301 grinder. A $0.1 \mathrm{~g}$ portion of the powder was extracted in a $2 \mathrm{ml}$ microfuge tube with $1 \mathrm{ml}$ of acetone/water $(50: 50, \mathrm{v} / \mathrm{v})$ as previously described. Extracts were kept in the dark at $4^{\circ} \mathrm{C}$ until use for determination of total phenolic content (TPC), total flavonoid content (TFC), and ferric reduction ability of plasma antioxidant activity (FRAP AA). All extractions were conducted in triplicate.

\subsection{Determination of TPC, TFC and FRAP AA Levels}

TPC was determined by the Folin-Ciocalteu assay [29,30] and TFC was determined using a colorimetric method [6] in 50- $\mu 1$ extraction samples as previously described [4]. Both TPC and TFC were expressed as $\mathrm{mg}+$ catechin equivalent/g sample through the calibration curve. Linearity ranges of the calibration curves were 5 to $200 \mu \mathrm{g} / \mathrm{ml}$ $(r=0.997)$ and 5 to $800 \mu \mathrm{g} / \mathrm{ml}(r=0.99)$ for TPC and TFC, respectively. The FRAP AA method was used to evaluate the antioxidant activity of chickpea extracts by measuring the ferric reducing ability of plasma at low $\mathrm{pH}$ levels [31]. Standard solutions of 0.1 to $1 \mathrm{mM}$ TROLOX (6-hydroxy-2,5,7,8-tetramethylchroman-2-carboxylic acid; Aldrich Germany) in methanol were prepared.

\subsection{Statistical Analysis}

All experiments were performed in triplicate. Data were analyzed by ANOVA using the statistical software package JMP Version 5.0. Tukey HSD multiple range test was carried out to detect significant differences between lines used, while Pearson correlation test was conducted to determine the correlation among variables. Significant levels were defined using $P \leq 0.05$.

\section{Results and Discussion}

\subsection{Effect of Baking on TPC, TFC and FRAP AA}

The effect of baking on TPC, TFC and FRAP AA in black desi and beige kabuli lines is shown in Figure 1. The levels of TPC, TFC and FRAP AA in whole dry seeds were lower than in our previous report [4]. As shown in Figure 1, flour, dough and bread made from black seeds 


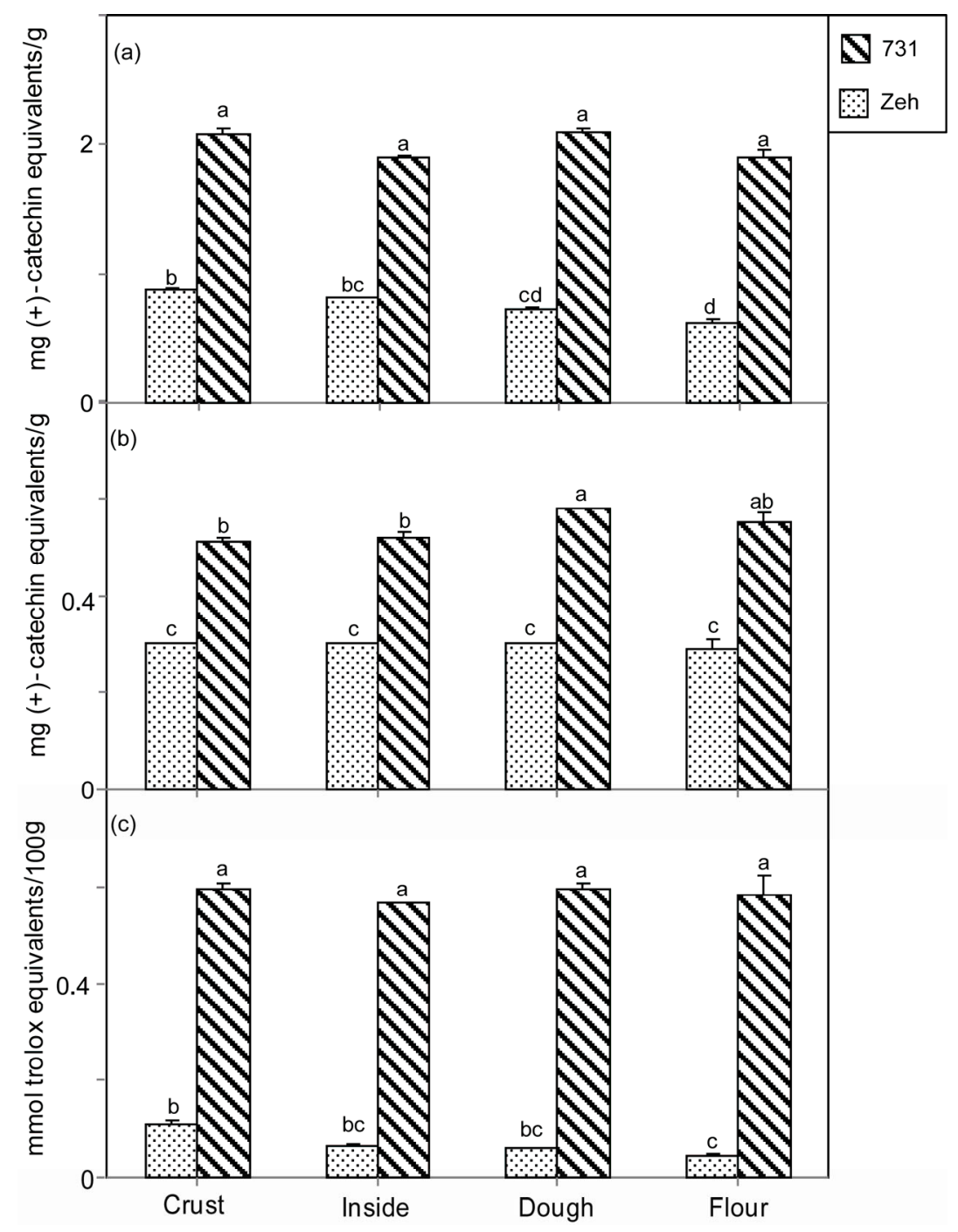

Figure 1. Effect of baking on total phenolic content (a), total flavonoid content (b) and antioxidant activity (c) in black desi line (731) and beige kabuli cv. Zehavit (Zeh) flour, dough and bread crust and inside parts. Bar represents mean \pm standard error from at least three replicates. Columns headed by the same small letter are not significantly different $(P<0.05)$.

(line 731) contained significantly higher levels, up to 3-, 2- and 13-fold, of TPC, TFC and FRAP AA, respectively, than those made from regular cream and beige-colored cv. Zehavit seeds (Figures 1(a)-(c)). In line 731, baking did not affect the levels of TPC or FRAP AA relative to the flour and dough, but slightly decreased the levels of TFC. This might be due to omission of a presoaking stage before baking, and thus no discarding of the baking water. These results strengthen our previous observation that polyphenols and flavonoids most likely leak into the surrounding water during the soaking and cooking processes [32]. In cv. Zehavit, however, a slight but significant increase in TPC and FRAP AA was observed in the bread crust. This might be due to the production of Maillard reaction products in the crust during thermal processing [33]. Similar observations have been made when baking rhubarb, whereby both TPC and FRAP AA were higher during the first $20 \mathrm{~min}$ and then decreased to low levels [34], and when baking chocolate cookies and chocolate cakes made with baking powder rather than baking soda $[35,36]$.

\subsection{Effect of Frying on TPC, TFC and FRAP AA}

The effect of frying on TPC, TFC and FRAP AA in black desi and beige kabuli lines is shown in Figure 2. Similar to baking, dry seeds, dough and fried falafel from black seeds (line 731) contained significantly higher levels, up to 3-, 2.6- and 14-fold, of TPC, TFC and FRAP AA, respectively, than those from regular cream-colored cv. Zehavit seeds (Figures 2(a)-(c)). Unfried dough from line 731 contained about $20 \%$ - 40\% lower levels of TPC, TFC and FRAP AA than dry seeds. This was expected 


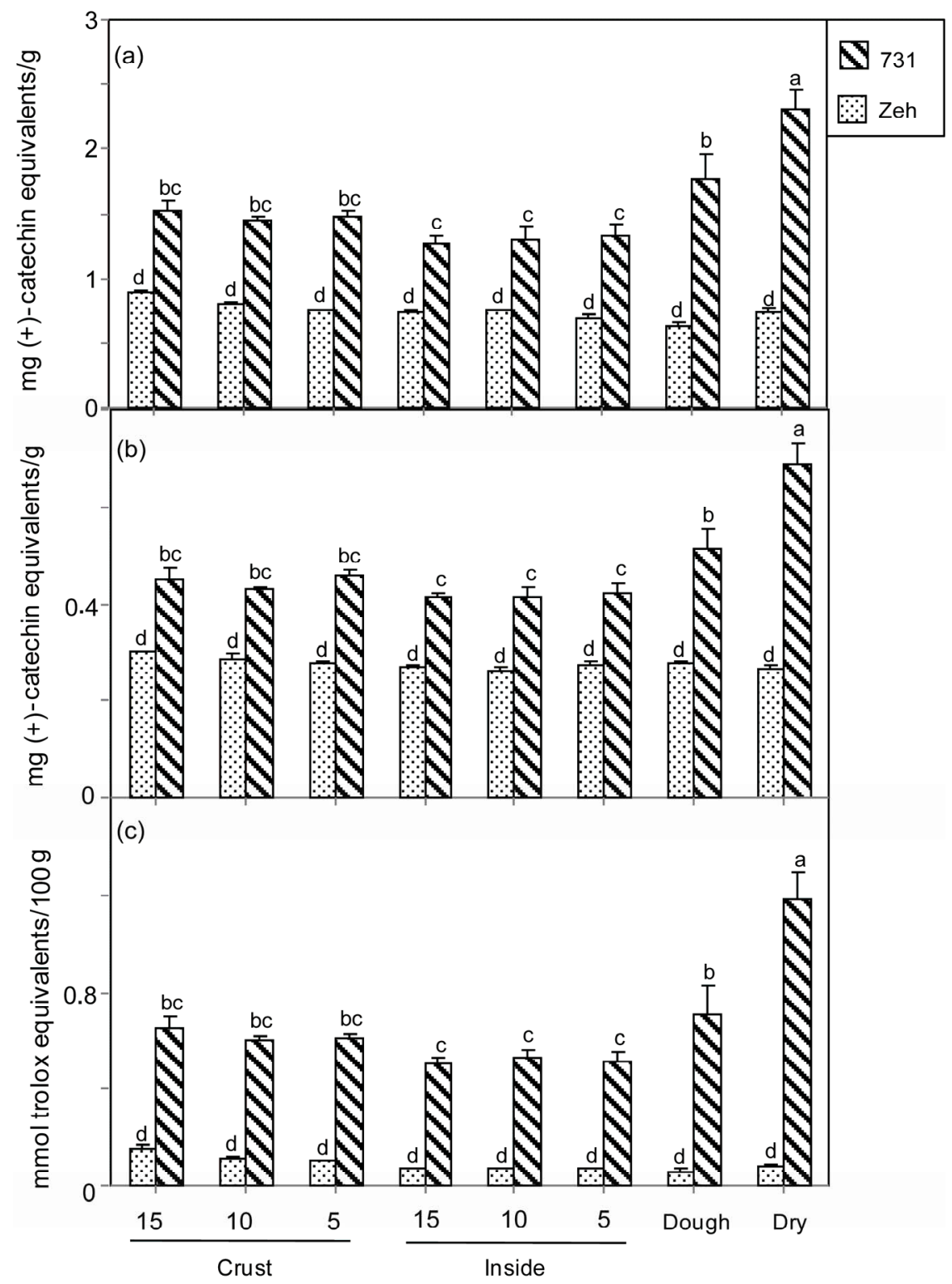

Figure 2. Effect of frying on total phenolic content (a), total flavonoid content (b) and antioxidant activity (c) in black desi line (731) and beige kabuli cv. Zehavit (Zeh) dry seeds, dough and crust and inside parts of the falafel ball. Bar represents means \pm standard error of at least three replicates. Columns headed by the same small letter are not significantly different $(P<$ 0.05).

because, in contrast to baking, frying chickpea falafel balls requires a presoaking treatment during which TPC and TFC leak into the soaking water $[21,32]$. In line 731 , frying resulted in a further significant decrease in all three studied parameters inside the fried balls, but not in the crust (Figures 2(a)-(c)). These reductions occurred only during the first $5 \mathrm{~min}$ of frying: longer frying did not cause changes in any of the three parameters. As solubility of polyphenols and flavonoids in oil is low, the reduction in TPC and TFC in the inside part of the falafel ball during frying might be due to degradation $[37,38]$. In cv. Zehavit, there were no significant changes in any of the three parameters in the fried treatments.

\subsection{Effect of Roasting on TPC, TFC and FRAP AA}

The effects of roasting chickpea seeds on their TPC, TFC and FRAP AA levels are shown in Figure 3. In the current study, two roasting methods were tested: wet roasting (Figures 3(a)-(c)) and dry roasting (Figures 3(d)-(f)). With all roasting treatments, roasted black seeds (line $731)$ contained significantly $(p<0.05)$ higher levels, up to 2.3-, 1.9- and 10-fold, of TPC, TFC and FRAP AA than the respective levels obtained for the regular cream- 


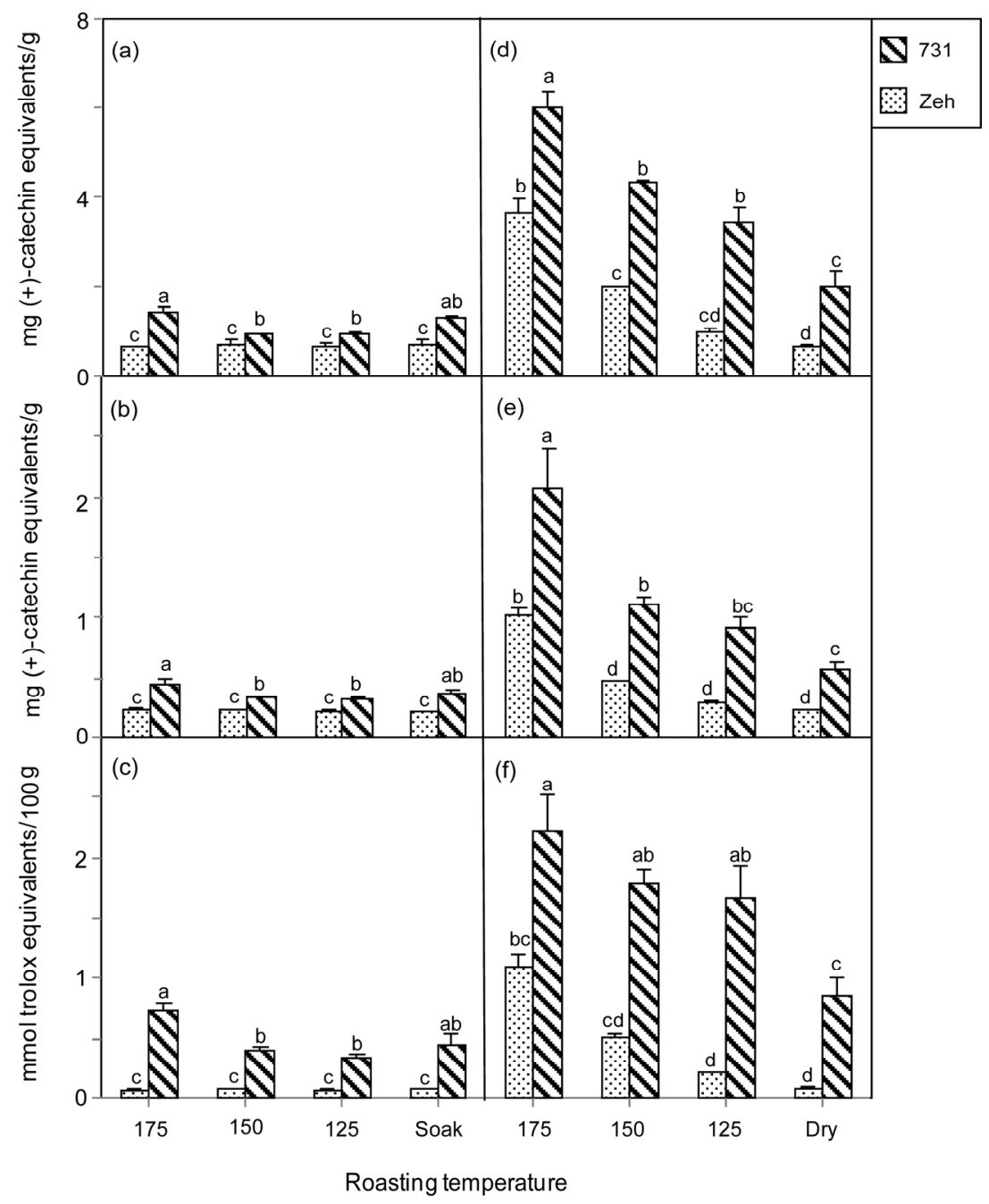

Figure 3. Effect of wet ((a)-(c)) and dry ((d)-(f)) roasting on total phenolic content ((a) and (d)), total flavonoid content ((b) and (e)) and antioxidant activity ((c) and (f)) in black desi line (731) and beige kabuli cv. Zehavit (Zeh) dry and soaked seeds and seeds roasted at different temperatures. Bar represents means \pm standard error of at least three replicates. Columns headed by the same small letter are not significantly different $(P<0.05)$.

colored seeds of cv. Zehavit (Figure 3). Results from the wet roasting resembled those of fried chickpeas (Figure 2), as both required a presoaking treatment which resulted in TPC and TFC leakage into the soaking water $[21,32]$. Wet roasting did not produce any significant changes in any of the three parameters in either line (Figures 3(a)-(c)). Dry roasting, in contrast to all other treatments performed in this study, resulted in a significant increase in TPC, TFC and FRAP AA in both line 731 and cv. Zehavit. This increase in levels of the three parameters was positively correlated with the increase in roasting temperature from $125^{\circ} \mathrm{C}$ to $175^{\circ} \mathrm{C}$ (Figures 3(d)(f)). The increase in all three parameters could result from release of bound polyphenols or from Maillard reaction products formed during roasting that have been reported to possess scavenging activity on reactive oxygen species $[39,40]$. Maillard reaction involves condensation reac- tions between sugars and amino acids and has been found to be linked to polyphenols [41] via inhibition of polyphenol oxidaze [42]. Similar observations of increased TPC and antioxidant activity with increased roasting temperature and duration have been found for carob powder [43] and apricot kernels [44].

\section{Conclusion}

Our results indicate that baking, frying and roasting colored chickpea seeds result in significantly higher levels of TPC, TFC and FRAP AA than in similarly treated cream- and beige-colored seeds. In contrast to our previous results with soaking and cooking, in which almost all TPC, TFC and FRAP AA leaked into the surrounding water [32], baking, frying and roasting retained most TPC, TFC and FRAP AA in the final products. Thus, colored chickpea subjected to any of these three processing methods 
might be considered a functional food, in addition to its traditional role of providing dietary proteins. Colored chickpea, due to its high antioxidant activity, might also contribute significantly to the management and/or prevention of degenerative diseases associated with free radical damage. Future research should be conducted to determine whether colored chickpeas can be used for management and/or prevention of such degenerative diseases.

\section{REFERENCES}

[1] U. Singh, N. Subrahmanyam and J. Kumar, "Cooking Quality and Nutritional Attributes of Some Newly Developed Cultivars of Chickpea (Cicer arietinum)," Journal of the Science of Food and Agriculture, Vol. 55, 1991, pp. 37-46. doi:10.1002/jsfa.2740550106

[2] B. Nizakat, B. K. Amal, S. S. K. Gul, M. Zahid and I. Ihsanullah, "Quality and Consumer Acceptability Studies and Their Inter-Relationship of Newly Evolved Desi Type Chickpea Genotypes (Cicer arietinum L.). Quality Evolution of New Chickpea Genotypes," International Journal of Food Science and Technology, Vol. 42, No. 5, 2007, pp. 528-534.

doi:10.1111/j.1365-2621.2006.01246.x

[3] P. B. Geil and J. W. Anderson, "Nutrition and Health Implications of Dry Beans, A Review," Journal of the American College of Nutrition, Vol. 13, No. 6, 1994, pp. 549-558.

[4] A. Segev, H. Badani, Y. Kapulnik, I. Shomer, M. OrenShamir and S. Galili, "Determination of Polyphenols, Flavonoids and Antioxidant Capacity in Colored Chickpea (Cicer arietinum L.)," Journal Food Science, Vol. 75, No. 2, 2010, pp. S115-S119. doi:10.1111/j.1750-3841.2009.01477.x

[5] A. Scalbert, C. Manach and C. Morand, "Dietary Polyphenols and the Prevention of Diseases," Critical Reviews in Food Science and Nutrition, Vol. 45, No. 4, 2005, pp. 287-306. doi:10.1080/1040869059096

[6] D. Heimler, P. Vignolini, M. G. Dini and A. Romani, "Rapid Tests to Assess the Antioxidant Activity of Phaseolus vulgaris L. Dry Beans," Journal of Agricultural and Food Chemistry, Vol. 53, No. 8, 2005, pp. 3053-3056. doi:10.1021/jf049001r

[7] L. Azevedo, J. C. Gomes, P. C. Stringheta, A. M. M. C. Gontijo, C. R. Padovani, L. R. Ribeiro and D. M. F. Salvadori, "Black Bean (Phaseolus vulgaris L.) as Protective Agent against DNA Damage in Mice," Food and Chemical Toxicology, Vol. 41, No. 12, 2003, pp. 1671-1676. doi:10.1016/S0278-6915(03)00173-X

[8] A. Cardador-Martínez, A. Albores, M. Bah, V. Calderón-Salinas, E. Castaño-Tostado, R. Guevara-González, A. Shimada-Miyasaka and G. Loarca-Piña, "Relationship among Antimutagenic Antioxidant and Enzymatic Activities of Methanolic Extract from Common Beans (Phaseolus vulgaris L.)," Plant Foods for Human Nutrition, Vol. 61, No. 4, 2006, pp. 161-168. doi:10.1007/s11130-006-0026-4

[9] A. Cardador-Martinez, G. Loacra-Pina and B. D. Oomah,
"Antioxidant Activity in Common Beans (Phaseolus vulgaris L.)," Journal of Agricultural and Food Chemistry, Vol. 50, No. 24, 2002, pp. 6975-6980.

doi:10.1021/jf020296n

[10] E. González de Mejía, E. Castaño-Tostado and G. LoarcaPiña, "Antimutagenic Effects of Natural Phenolic Compounds in Beans," Mutation Research-Genetic Toxicology and Environmental Mutagenesis, Vol. 441, No. 1, 1999, pp. 1-9. doi:10.1016/S1383-5718(99)00040-6

[11] X. Aparicio-Fernández, R. Reynoso-Camacho, E. Castaño-Tostado, T. García-Gasca, E. González de Mejía, S. Guzmán-Maldonado, G. Elizondo, G. G. Yousef, M. A. Lila and G. Loarca-Piña, "Antiradical Capacity and Induction of Apoptosis in HeLa Cells by a Phaseolus vulgaris Extract," Plant Foods for Human Nutrition, Vol. 63, 2008, pp. 35-40. doi:10.1007/s11130-007-0066-4

[12] X. Aparicio-Fernandez, T. Garcia-Gasca, G. G. Yousef, M. A. Lila, E. Gonzalez de Mejia and G. Loarca-Pina. "Chemopreventive Activity of Polyphenolics from Black Jamapa Bean (Phaseolus vulgaris L.) on HeLa HaCaT Cells," Journal of Agricultural and Food Chemistry, Vol. 54, 2006, pp. 2116-2122. doi:10.1021/jf052974m

[13] M. Dong, X. He and R. H. Liu, "Phytochemicals of Black Bean Seed Coats: Isolation, Structure Elucidation and Their Antiproliferative and Antioxidative Activities," Journal of Agricultural and Food Chemistry, Vol. 55, No. 20, 2007, pp. 6044-6051. doi:10.1021/jf070706d

[14] R. Amarowicz and B. Raab, "Antioxidative Activity of Leguminous Seed Extracts Evaluated by Chemiluminescence Methods," Zeitschrift fur Naturforschung, Vol. 52, No. 10, 1997, pp. 709-712.

[15] M. Carbonaro, F. Virgili and E. Carnovale, "Evidence for Protein-Tannin Interaction in Legumes: Implications in the Antioxidant Properties of Faba Bean Tannins," Lebensmittel-Wissenschaft und Technologie, Vol. 29, No. 8, 1996, pp. 743-750. doi:10.1006/fstl.1996.0116

[16] F. Shahidi, U. D. Chavan, M. Naczk and R. Amarowicz, "Nutrient Distribution and Phenolic Antioxidants in AirClassified Fractions of Beach Pea (Lathyrus maritimus L.)," Journal of Agricultural and Food Chemistry, Vol. 49, No. 2, 2001, pp. 926-933. doi:10.1021/if0005317

[17] P. D. Duh, W. J. Yen, P. C. Du and G. C. Yen, "Antioxidant Activity of Mung Bean Hulls," Journal of the American Oil Chemists Society, Vol. 74, No. 9, 1997, pp. 1059-1063. doi:10.1007/s11746-997-0025-0

[18] R. Amarowicz, M. Karamac and U. Chavan, "Influence of the Extraction Procedure on the Antioxidative Activity of Lentil Seed Extracts in a b-Carotene-Linoleate Model System," Grasas y Aceites, Vol. 52, 2001, pp. 89-93. doi:10.3989/gya.2001.v52.i2.378

[19] Y. Shem-Tov, S. Galili, H. Badani, A. Segev, I. Hedvat and R. Hovav, "Determination of Total Polyphenol, Flavonoid and Anthocyanin Contents and Antioxidant Capacities of Skins from Peanut (Arachis hypogaea) Lines with Different Skin Colors," Journal of Food Biochemistry, 2011, Article in Press.

[20] H. Han and B.-K. Baik, "Antioxidant Activity and Phenolic Content of Lentils (Lens culinaris), Chickpeas (Cicer arietinum L.), Peas (Pisum sativum L.) and Soybeans 
(Glycine max) and Their Quantitative Changes during Processing," International Journal of Food Science and Technology, Vol. 43, No. 11, 2008, pp. 1971-1978. doi:10.1111/j.1365-2621.2008.01800.x

[21] B. Xu and S. K. C. Chang, "Effect of Soaking, Boiling and Steaming on Total Phenolic Content and Antioxidant Activities of Cool Season Food Legumes," Food Chemistry, Vol. 110, No. 1, 2008, pp. 1-13. doi:10.1016/j.foodchem.2008.01.045

[22] B. J. Xu and S. K. C. Chang, "A Comparative Study on Phenolic Profiles and Antioxidant Activities of Legumes as Affected by Extraction Solvents," Journal of Food Science, Vol. 72, No. 2, 2007, pp. S159-S166. doi:10.1111/j.1750-3841.2006.00260.x

[23] M. Kaur, N. Singh and N. Singh Sodhi, "Physicochemical, Cooking, Textural and Roasting Characteristics of Chickpea (Cicer arietinum L.) Cultivars," Journal of Food Engineering, Vol. 69, No. 4, 2005, pp. 511-517. doi:10.1016/j.jfoodeng.2004.09.002

[24] K. K. Bhat and S. Bhattacharya, "Deep Fat Frying Characteristics of Chickpea Flour Suspensions," International Journal of Food Science and Technology, Vol. 36, 2001, pp. 499-507. doi:10.1046/j.1365-2621.2001.00455.x

[25] M. Gómeza, B. Olietea, C. M. Rosellb, V. Pandoc and E. Fernández, "Studies on Cake Quality Made of WheatChickpea Flour Blends," Food Science and Technology, Vol. 41, No. 9, 2008, pp. 1701-1709.

[26] Ö. Ç. Açar, V. Gökmen, N. Pellegrini and V. Fogliano, "Direct Evaluation of the Total Antioxidant Capacity of Raw and Roasted Pulses, Nuts and Seeds," European Food Research and Technology, Vol. 229, No. 6, 2009, pp. 961-969. doi:10.1007/s00217-009-1131-Z

[27] C. F. Chau, P. C. Cheung and Y. S. Wong, "Effect of Cooking on Content of Amino Acids and Antinutrients in Three Chinese Indigenous Legume Seeds," Journal of the Science of Food and Agriculture, Vol. 75, 1997, pp. 447452.

doi:10.1002/(SICI) 1097-0010(199712)75:4<447::AID-JS FA896>3.0.CO;2-5

[28] C. K. Hira and N. Chopra, "Effects of Roasting on Protein Quality of Chickpea (Cicer arietinum) and Peanut (Arachis hypogaea)," Journal of Food Science and Technology, Vol. 32, 1995, pp. 501-503.

[29] V. L. Singleton, R. Orthofer and R. M. Lamuela-Raventos, "Analysis of Total Phenols and other Oxidation Substrates and Antioxidants by Means of Folin-Ciocalteu Reagent," Methods in Enzymology, Vol. 299, 1999, pp. 152-178. doi:10.1016/S0076-6879(99)99017-1

[30] V. L. Singleton and J. A. Rossi, "Colorimetry of Total Phenolic with Phosphomolybdicphosphotungstic Acid Reagents," American Journal of Enology and Viticulture, Vol. 16, No. 3, 1965, pp. 144-158.

[31] I. F. F. Benzie and J. J. Strain, "The Ferric Reducing Ability of Plasma (FRAP) as a Measure of Antioxidant Power: The FRAP Assay," Analytical Biochemistry, Vol. 239, No. 1, 1996, pp. 70-76. doi:10.1006/abio.1996.0292

[32] A. Segev, H. Badani, L. Galili, R. Hovav, Y. Kapulnik, I. Shomer and S. Galili, "Total Phenolic Content and Anti- oxidant Activity of Chickpea (Cicer arietinum L.) as Affected by Soaking and Cooking Conditions," Food and Nutrition Sciences, Vol. 2, 2011, pp. 724-730. doi:10.4236/fns.2011.27099

[33] M. Lindenmeier and T. Hofmann, "Influence of Baking Conditions and Precursor Supplementation on the Amounts of the Antioxidant Pronyl-L-Lysine in Bakery Products," Journal of Agricultural and Food Chemistry, Vol. 52, 2004, pp. 350-354. doi:10.1021/jf0346657

[34] G. J. McDougall, P. Dobson and N. Jordan-Mahy, "Effect of Different Cooking Regimes on Rhubarb Polyphenols," Food Chemistry, Vol. 119, 2010, pp. 758-764. doi:10.1016/j.foodchem.2009.07.030

[35] K. B. Miller, D. A. Stuart, N. L. Smith, C. Y. Lee, N. L. Mchale, J. A. Flanagan, B. Ou and W. J. Hurst, "Antioxidant Activity and Polyphenol and Procyanidin Contents of Selected Commercially Available Cocoa-Containing and Chocolate Products in the United States," Journal of Agricultural and Food Chemistry, Vol. 54, No. 11, 2006, pp. 4062-4068. doi:10.1021/jf060290o

[36] L. Stahl, K. B. Miller, J. Apgar, D. S. Sweigart, D. A. Stuart, N. McHale, B. Ou, M. Kondo and W. J. Hurst. "Preservation of Cocoa Antioxidant Activity, Total Polyphenols, Flavan-3-ols, and Procyanidin Content in Foods Prepared with Cocoa Powder," Journal of Food Science, Vol. 74, No. 6, 2009, pp. C456-C461. doi:10.1111/j.1750-3841.2009.01226.x

[37] D. P. Makris and J. T. Rossiter, "Domestic Processing of Onion Bulbs (Allium cepa) and Asparagus Spears (Asparagus officinalis): Effect on Flavonol Content and Antioxidant Status," Journal of Agricultural and Food Chemistry, Vol. 49, No. 7, 2001, pp. 3216-3222. doi:10.1021/jf001497z

[38] K. R. Price and M. J. C. Rhodes, "Analysis of the Major Flavonol Glycosides Present in Four Varieties of Onion (Allium cepa) and Changes in Composition Resulting from Autolysis," Journal of the Science of Food and Agriculture, Vol. 74, No. 3, 1997, pp. 331-339.

doi:10.1002/(SICI)1097-0010(199707)74:3<331::AID-JS FA806>3.0.CO;2-C

[39] F. Hayase, S. Hirashima, G. Okamoto and H. Kato, "Scavenging of Active Oxygens by Melanoidins," Agricultural and Biological Chemistry, Vol. 54, No. 6, 1990, pp. 855-862.

[40] G. C. Yen and P. P. Hsieh, "Antioxidative Activity and Scavenging Effects on Active Oxygen of Xylose-Lysine Maillard Reaction Products," Journal of the Science of Food and Agriculture, Vol. 67, 1995, pp. 415-420. doi:10.1002/jsfa. 2740670320

[41] A. Jokic, M. C. Wang, C. Liu, A. I. Frenkel and P. M. Huang, "Integration of the Polyphenol and Maillard Reactions into a Unified Abiotic Pathway for Humification in Nature: the Role of Delta- $\mathrm{MnO}_{2}$," Organic Geochemistry, Vol. 35, No. 6, 2004, pp. 747-762. doi:10.1016/j.orggeochem.2004.01.021

[42] M. K. Lee and I. Park, "Inhibition of Potato Polyphenol Oxidase by Maillard Reaction Products," Food Chemistry, Vol. 91, 2005, pp. 57-61. doi:10.1016/j.foodchem.2004.05.046 
[43] H. Sahin, A. Topuz, M. Pischetsrieder and F. Ozdemir, "Effect of Roasting Process on Phenolic, Antioxidant and Browning Properties of Carob Powder," European Food Research and Technology, Vol. 230, No. 1, 2009, pp. 155-161. doi:10.1007/s00217-009-1152-7
[44] G. Durmaz and M. Alpaslan, "Antioxidant Properties of Roasted Apricot (Prunus armeniaca L.) Kernel," Food Chemistry, Vol. 100, No. 3, 2007, pp. 1177-1181. doi:10.1016/j.foodchem.2005.10.067 